\title{
Staphylococcus aureus and Pseudomonas aeruginosa- Biofilm formation Methods
}

\author{
A. R. Rewatkar, Dr. B. J. Wadher \\ P.G.T. Department of Microbiology, L.I.T. Premises, Rashtrsant Tukdoji Maharaj Nagpur University, Nagpur- \\ 440033, Maharashtra, India
}

\begin{abstract}
For the detection of Biofilm formation method, total 60 clinical isolates viz. Staphylococcus aureus, Pseudomonas aeruginosa were used. Clinical isolates were identified as per standard microbiological procedure. Antibiotic susceptibility test of biofilm producing bacteria was performed by using the Kirby-Baner disc diffusion technique. Biofilm detection was tested by Tube method (TM), Congo Red Agar method (CRA). These methods require the use of especially solid media-brain heart infusion broth supplemented with 5\% sucrose and Congo red strain. Out of 60 isolates, CRA method detected 54 as high biofilm producer while by TM method, 50 isolates showed trong biofilm formation, and non biofilm producer were 10. According to the antibiotic susceptibility test, higher antibiotic resistance was observed in biofilm producing bacteria than non biofilm producers. Hence from the current investigation, CRA method is rapid, sensitive and reproducible. TM method gave moderate results. So CRA method is more suitable method for detection of biofilm formation as compared to the other method in the present investigation.
\end{abstract}

Keywords: Biofilm, congo red agar method, Pseudomonas aeruginosa, Staphylococcus aureus, tube method,

\section{Introduction:-}

Biofilm are defined as microbial derived sessile communities characterized by the cells that are irreversibly attached to a substratum or to each other. (Donlon et.al. 2002) Biofilm are densely packed multicellular communities of microorganisms attached to a surface or interface. Bacteria seem to initiate biofilm formation in response to specific environmental cues, such as nutrient and oxygen availability. Biofilm are the source of persistent infections of many pathogenic microbes. They are responsible for much nosocomial infection and also associated with many medical conditions including indwelling medical device, dental plaque, upper respiratory tract infection and urogenital infection. (Costerton et.al. 1999 and Reid G.1999)

Several factors such as exotoxins, surface proteins and extracellular polysaccharides having important roles in virulence of $S$. aureus isolated from mastitis cases have been reported. Furthermore, it has been determined that production of slime factor in S. aureus strains causing mastitis was an important virulence factor affecting pathogenesis. It is considered that the first step in mastitis progress is adhesion of $S$. aureus to mammary epithelial cells and slime factor plays an important role for adhesion and colonization. Production of slime factor also plays an important role in antibiotic resistance and it has been reported that slime producing strains are more resistant to antibiotics than non-slime producing strains. (Basegela et.al.1993, Vasudevan P. et.al.2003,Amorena B. et.al 1999)

All microbes like Gram positive and Gram negative bacteria have capacity to synthesized biofilm. Bacteria commonly involved include Staphylococcus aureus, Staphylococcus epidermidis, Streptococcus viridans, Escherichia coli, Enterococcus faecalis Klebsiella pneumoniae, Proteus mirabilis and Pseudomonas aeruginosa. (Donlon R.M.2001)

There are various methods to detect biofilm production. These include the

Tissue Culture Plate (TCP), Tube method (TM), Congo Red Agar method (CRA), bioluminescent assay, piezoelectric sensors, and fluorescent microscopic examination.(Christensen et al. 1995, Freeman J. 1989)

Multidrug-resistant organisms have been reported worldwide and are now recognized as one of the most difficult healthcare-associated infections to control and to treat. (Tabassum S. 2007)

Study of microbial biofilms has received significance attention over the past decades. Therefore, studies and diagnostic methods identifying virulent bacterial strains, i.e., strains with a capacity for slime production. Consequent biofilm formations are necessary to develop effective strategies for biofilm control and improvement of patient care. 
1) Selection of isolates:

\section{Material and method}

A total 60 clinical isolates were subjected to biofilm detection method. Samples were collected from urinary catheters tips, intravenous catheter tips, few pus specimen, sputum samples etc. The entire specimens were received from patients with nosocomial infection admitted to the hospital.

Isolates were identified by Standard microbiological procedure(Gram staining, cultural characteristics, catalase test, oxidase test, motility, biochemical test ). In current study, Staphylococcus aureus and Pseudomonas aeruginosa were used as a control.

\section{2) Biofilm Detection Methods:}

Biofilm detection was carried out by the following methods;

\section{a) Tube method (TM)}

This is a qualitative method for biofilm detection. A loopful of test organisms inoculated in $10 \mathrm{ml}$ of trypticase soy broth with $1 \%$ glucose in test tubes. Incubate the tubes at $37^{\circ} \mathrm{C}$ for $24 \mathrm{~h}$. After incubation, tubes were decanted and washed with phosphate buffer saline $(\mathrm{pH} 7.3)$ and dried. Tubes were then stained with crystal violet $(0.1 \%)$. Wash excess stain with distilled water. Tubes were dried in inverted position. The scoring for tube method was done according to the results of the control strains. Biofilm formation was considered positive when a visible thick film lined the wall and the bottom of the tube.

\section{b) Congo Red Agar method (CRA)}

CRA medium was prepared with brain heart infusion broth $37 \mathrm{~g} / \mathrm{L}$, sucrose $50 \mathrm{~g} / \mathrm{L}$, agar $10 \mathrm{~g} / \mathrm{L}$ and Congo Red indicator $8 \mathrm{~g} / \mathrm{L}$. Congo Red stain was prepared as a concentrated aqueous solution and autoclaved separately from the other medium constituents. Then it was added to the autoclaved brain heart infusion agar with sucrose. Inoculate CRA plates with test organisms and incubate at $37^{\circ} \mathrm{C}$ for $24 \mathrm{~h}$ aerobically. Black colonies indicate biofilm production. (Freeman et al.1989).

\section{3) Antibiotic Susceptibility Test}

Antibiotic susceptibility test of biofilm producing bacteria was done on Mueller Hinton agar using the following antibiotic discs: ampicillin colostin, naficillin, nalidixic acid, streptomycin, methicillin, chloramphenicol, clindamycin, cefoxamine, rifampicin, cloxacillin, vancomycin, erythromycin, oxacillin, penicillin. All antibiotic discs were used against Pseudomonas aeruginosa ATCC 27333 and Staphylococcus aureus ATCC 12228 as control strains.

\section{Result and Discussion}

Out of 60 isolates, 30 were Gram positive pathogens and 30 were Gram negative biofilm producers. Gram positive includes Staphylococcus aureus while Gram negative includes Pseudomonas aeruginosa. All these isolates were identified and characterized by standard microbiological procedure. These isolates mainly isolated from various clinical samples including medical devices, urinary catheter tips, urine sample, blood, pus, sputum, etc. Table no.1 gave an idea regarding biofilm producing microbes mainly resides in particular area.

\begin{tabular}{|c|c|c|}
\hline Organisms & Clinical samples & Biofilm production \\
\hline P. aeruginosa & Urine & Strong \\
\hline P. aeruginosa & Catheter tips & Strong \\
\hline P. aeruginosa & Blood & Strong \\
\hline P. aeruginosa & ET secretion & Strong \\
\hline S. aureus & Urine & Strong \\
\hline S. aureus & Pus & Strong \\
\hline S. aureus & Sputum & Moderate \\
\hline E. coli & Urinary catheter tips & Strong \\
\hline E. coli & Urine & Strong \\
\hline S. epidermis & sputum & Strong \\
\hline
\end{tabular}

Table 1. Correlation of biofilm production of isolates from various clinical samples

Biofilm producing pathogens were determined by various methods. In the current study, Tube method (TM), Congo Red Agar methods (CRA) were used. 
By Tube method, visible thick film was obtained inside the wall of tube and bottom of the tube. 50 isolates were shown thick film inside the wall of the tube indicating strong biofilm production while 10 isolates were not shown biofilm formation. (fig. no.1)

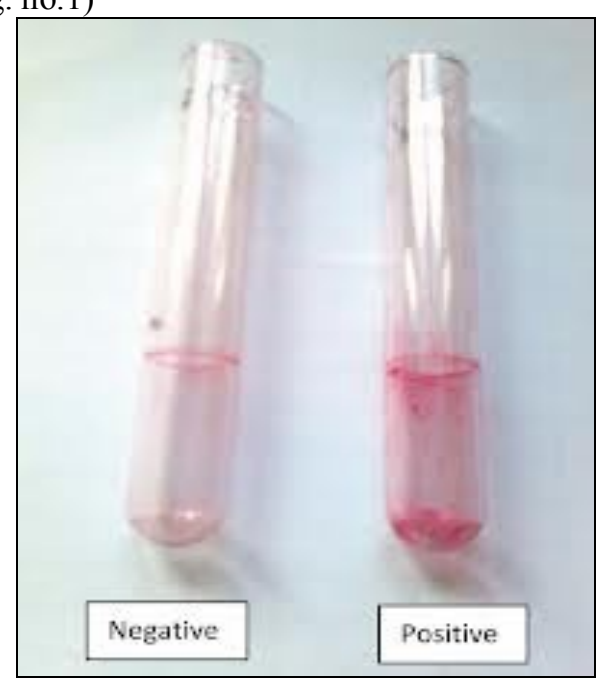

Figure no.1- Tube method. Thick film formation gives positive result while thin film formation gives non biofilm producers.

By Congo red agar method, black colour colonies were observed for the biofilm production. 54 isolates gave black colour colonies on Congo red agar plate while only 06 isolates gave pink colour colonies indicating non biofilm production. (fig.no.2)

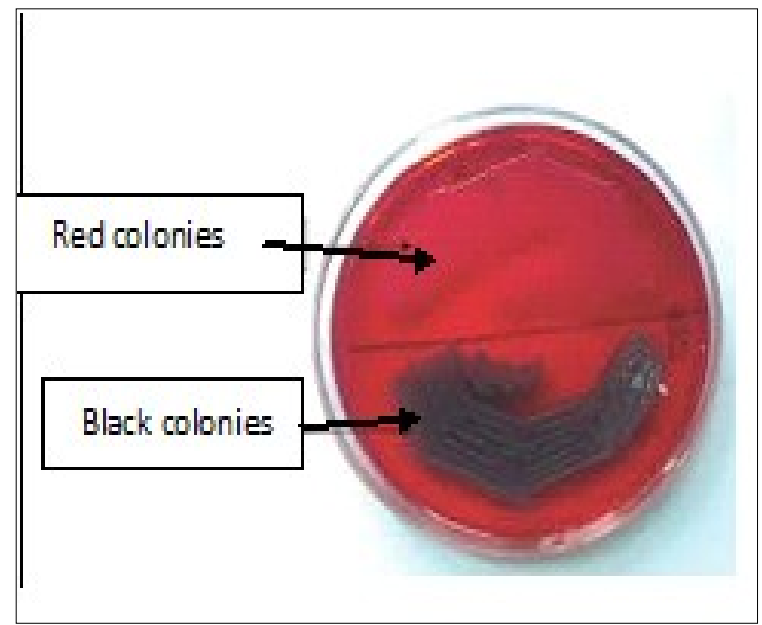

Figure no.2- Congo red agar method Black colonies shows biofilm formation While red colonies shows non biofilm producers.

According to these methods, number of isolates gave biofilm producers and nonbiofilm producers shown in table no. 2. Comparative chart of biofilm production by tube method, Congo red agar method was given in Table no. 3

\begin{tabular}{|c|c|c|c|}
\hline Sr .no. & Methods & Biofilm production & $\begin{array}{l}\text { Nonbiofilm } \\
\text { production }\end{array}$ \\
\hline \multirow{4}{*}{$\begin{array}{c}1 \\
N=60\end{array}$} & Tube method (TM) & & \\
\hline & Gram positive isolates & 25 & 05 \\
\hline & Gram negative isolates & 25 & 05 \\
\hline & Total $(\mathrm{n})$ & 50 & 10 \\
\hline \multirow{4}{*}{$\begin{array}{c}2 \\
N=60\end{array}$} & Congo red agar method (CRA) & & \\
\hline & Gram positive isolates & 27 & 03 \\
\hline & Gram negative isolates & 27 & 03 \\
\hline & Total(n) & 54 & 06 \\
\hline
\end{tabular}


Table no. 2: Comparative study of different biofilm detection methods.

\begin{tabular}{|c|c|c|c|}
\hline \multirow{4}{*}{$\begin{array}{c}\text { No. of isolates } \\
(60)\end{array}$} & $\begin{array}{c}\text { Biofilm } \\
\text { production }\end{array}$ & TM(\%) & CRA(\%) \\
\cline { 2 - 4 } & Strong & $84 \%$ & $90 \%$ \\
\cline { 2 - 4 } & Weak/none & $16 \%$ & $10 \%$ \\
\hline
\end{tabular}

Table no. 3. Biofim production by tube method, Congo red agar method.

Pseudomonas aeruginosa, S. aureus, produces strong biofilm by various methods and these microbes are highly resistant to various antibiotics. These multidrug resistant biofilm producing microbes given in observation table no. 4 and 5 .

\begin{tabular}{|c|c|c|c|}
\hline $\begin{array}{c}\text { Sr.n } \\
\text {. }\end{array}$ & Antiobiotic & $\begin{array}{c}\text { Biofilm producing Gram- } \\
\text { positive organisms \% }\end{array}$ & $\begin{array}{c}\text { Non-biofilm producing } \\
\text { Gram-positive organisms } \\
\%\end{array}$ \\
\hline 1 & Colisitn & 90 & 90 \\
\hline 2 & Ampicillin & 85 & 30 \\
\hline 3 & Nafcillin & 60 & 50 \\
\hline 4 & Nalidixic acid & 45 & 30 \\
\hline 5 & Penicillin G & 60 & 55 \\
\hline 6 & Methicillin & 85 & 80 \\
\hline 7 & vancomycin & 0 & 0 \\
\hline
\end{tabular}

Table no.4:- Resistance pattern of Gram positive bacteria $(n=30)$

\begin{tabular}{|c|c|c|c|}
\hline $\begin{array}{c}\text { Sr. } \\
\text { no. }\end{array}$ & Antiobiotic & $\begin{array}{c}\text { Biofilm producing Gram- } \\
\text { negative organisms \% }\end{array}$ & $\begin{array}{c}\text { Biofilm producing Gram- } \\
\text { negative organisms \% }\end{array}$ \\
\hline 1 & Ampicillin & 90 & 90 \\
\hline 2 & Ciprofloxacin & 95 & 65 \\
\hline 3 & Amikacin & 65 & 30 \\
\hline 4 & Aztreonam & 80 & 65 \\
\hline 5 & Cotriaxom & 55 & 33 \\
\hline 6 & Meropenem & 0 & 0 \\
\hline 7 & Colistin & 0 & 0 \\
\hline
\end{tabular}

Table no.5:- Resistance pattern of Gram negative bacteria $(\mathrm{n}=30)$

Biofilm producing bacteria are responsible for many recalcitrant infections and are notoriously difficult to eradicate. They exhibit resistance to antibiotics by various methods like restricted penetration of antibiotic into biofilms, decreased growth rate and expression of resistance genes. There are various methods for biofilm detection. In this study 60 isolates evaluated by three screening methods for their ability to form biofilms.

From this study Congo red agar method gave significant result $90 \%$ strong biofilm production as compared to the Tube Method (83\%). Biofilm producing bacteria were isolated from various specimens like urine, sputum, pus, ET secretion, blood. But most of biofilm producing microbes are from urine samples and urinary catheters tips.

Donlan 2002 reported in his study the association of biofilm producing bacteria with urinary catheters .(Ruzika F. et.al. 2004,) In another study, Ruzicka et al. noted that out of 147 isolates of S. epidermidis, TM detected biofilm formation (53.7\%) and CRA detected in $64(43.5 \%)$ isolates. They showed that TM is better for biofilm detection than CRA. Baqai et al. tested TM to detect biofilm formation among uropathogens. According to their results, $75 \%$ of the isolates exhibited biofilm formation. (Tabassum S. (2007))

Knobloch et al. did not recommend the CRA method for biofilm detection in their study. Out of 128 isolates of $S$. aureus, CRA detected only $3.8 \%$ as biofilm producers as compared to TCP which detected $57.1 \%$ as biofilm producing bacteria.( Vasudevan P. et.al. 2003)

In current study, the majority of biofilm producing bacteria was from urinary catheter tips. Most of the microbes are from common sources like pus samples, sputum samples, ET secretion. These microbes produce biofilm and causes nosocomial infection which is chronic to the patients. These microbes are also multidrug resistant. Therefore there is a need to find out a suitable method for detection of biofilm producing microbes.

From this study, we have concluded that TM and CRA method is more qualitative and reliable method to detect biofilm producing microorganisms. TM and CRA method is used as a general screening method for detection of biofilm producing bacteria in laboratories. 


\section{References}

[1]. Amorena, B.; Gracia, E.; Monzon, M.; Leiva, J.; Oteiza, C.; Perez, M Alabart, J.L.; Hernandez-Yago, J. (1999). Antibiotic susceptibility assay for Staphylococcus aureus in biofilms developed in vitro. J. Antimicrob. Chemother. 44, 43-55.

[2]. Baqai R, Aziz M, Rasool G. (2008) Urinary tract infection in diabetic patients and biofilm formation of uropathogens. Infect Dis J Pakistan. 17(1):7-9.

[3]. Baselga, R.; Albizu, I.; De La Cruz, M.; Del Cacho, E.; Barberan, M.; Amorena, B. (1993). Phase variation of slime production in Staphylococcus aureus: implications in colonization and virulence. Infect. Immun. 61 (11), 4857-4862.

[4]. Christensen GD, Simpson WA, Younger JA et al. (1995) Adherence of coagulase negative Staphylococci to plastic tissue cultures: a quantitative model for the adherence of Staphylococci to medical devices. J Clin Microbiol;22:996-1006.

[5]. Christensen GD, Simpson WA, Bisno AL, Beachey EH.( 1982) Adherence of slime producing strains of Staphylococcus epidermidis to smooth surfaces. Infect Immun; 37:318-26

[6]. Costerton, J.W., Stewart, P. S., and Greenberg, E. P. (1999).:Bacterial biofilms: a common cause of persistent infections.Science, 284, 1318-1322.

[7]. Donlan RM, Costerton W. (2002) Biofilms: Survival mechanisms of clinically relevant Microorganisms. Clin Microbiol Rev; 15(2):167-93.)

[8]. Donlan RM. (2001) Biofilms and device-associated infections. Emerg Infect Dis; 7(2): 277-81.

[9]. Freeman J, Falkiner FR, Keane CT. (1989)New method for detecting slime production by coagulase negative staphylococci. J Clin Pathol; 42:872-4

[10]. Knobloch JK, Horsetkotte MA, Rohde H, Mack D. 92002)Evaluation of different detection methods of biolfilm formation in Staphylococcus aureus. Med Microbial Immunol; 191(2):101-6

[11]. Reid G. (1999) Biofilms in infectious disease and on medical devices. Int. J. Antimic Ag; 11:223-6.

[12]. Ruzicka F, Hola V, Votava M et al. (2004) Biofilm detection and clinicalsignificance of Staphylococcus epidermidis isolates. Folia Microbiol (Praha); 49(5):596-600.

[13]. Tabassum S. (2007)Multidrug-resistant acinetobacter: a major nosocomial pathogen challenging physicians. Bangladesh J Med Microbiol, 1, 65-68

[14]. Vasudevan, P.; Nair, M.K.M.; Annamalai, T.; Venkitanarayanan, K.S. (2003). Phenotypic and genotyping characterization of bovine mastitis isolates of Staphylococcus aureus for biofilm formation. Vet. Microbiol. 92, 179-185. 